\title{
Politics and Nonverbal Cues: A Natural Pairing- Introduction to the Special Issue
}

\author{
Joann M. Montepare
}

Published online: 3 February 2010

(C) Springer Science+Business Media, LLC 2010

The Journal of Nonverbal Behavior is pleased to present this Special Issue on Politics and Nonverbal Cues. Aristotle argued that by nature we are political animals. Other scholars would agree that we are also social animals driven by interpersonal exchange. Thus, the pairing of politics with nonverbal cues is a natural one, and in a world filled with political competition and conflict it is a necessary relationship to acknowledge and understand better.

In the provocative feature paper, Olivola and Todorov (2010) reinforce the finding that extremely rapid personality judgments of political candidates based solely on their appearance can predict their electoral success. In doing so, they examine the pivotal role of perceived facial competence and introduce a computer model to explore and test other mediating facial cues. In the spirit of political debate, three commentaries respond to Olivola and Todorov (2010), challenging their conclusions and offering additional positions to consider. Verhulst et al. (2010) concur with the notion that superficial cues can drive political outcomes; however, they call for a closer look at pathways determined by facial attractiveness and its concomitant effects. Riggio and Riggio (2010) direct our attention to the likely evolutionary roots of these swift, automatic judgments and the extent to which other evolved pathways characterized by conscious control and motivation might be used to moderate them. Lieb and Shah (2010) urge for a more contextual analysis of the implications of political snap judgments by way of culture, campaign systems and candidate management.

This issue is surely one that will generate discussion and debate, in addition to calling for even more attention to research into our political nature and nonverbal behavior.

J. M. Montepare (ه)

RoseMary B. Fuss Center for Research on Aging and Intergenerational Studies, Lasell College, 1844 Commonwealth Avenue, Newton, MA 02466, USA

e-mail: jmontepare@lasell.edu 


\section{References}

Lieb, K., \& Shah, D. (2010). Consumer culture theory, nonverbal communication, and contemporary politics: Considering context and embracing complexity. Journal of Nonverbal Behavior, 34. doi: 10.1007/s10919-010-0085-y.

Olivola, C., \& Todorov, A. (2010). Elected in 100 milliseconds: Appearance-based trait inferences and voting. Journal of Nonverbal Behavior, 34. doi:10.1007/s10919-009-0082-1.

Riggio, H. R., \& Riggio, R. (2010). Appearance-based trait inferences and voting: Evolutionary roots and implications for leadership. Journal of Nonverbal Behavior, 34. doi:10.1007/s10919-009-0083-0.

Verhulst, B., Lodge, M., \& Lavine, H. (2010). The attractiveness halo: Why some candidates are perceived more favorably than others. Journal of Nonverbal Behavior, 34. doi:10.1007/s10919-009-0084-z. 